\title{
Heart Transplantation in Patients Older than 65 Years: Worthwhile or Wastage of Organs?
}

\author{
David Prieto ${ }^{1}$ Pedro Correia ${ }^{1} \quad$ Manuel Batista ${ }^{1}$ Manuel de Jesus Antunes ${ }^{1}$ \\ 1 Department of Cardiothoracic Surgery and Transplantation of \\ Thoracic Organs, University Hospital and Faculty of Medicine \\ Coimbra, Portugal \\ Thorac Cardiovasc Surg

\begin{abstract}
Address for correspondence Manuel de Jesus Antunes, MD, PhD, DSc, Department of Cardiothoracic Surgery, Hospital Da Universidade, Praceta Mota Pinto, Coimbra 3049, Portugal (e-mail: antunes.cct.chuc@sapo.pt).
\end{abstract}

\begin{abstract}
Background Patients older than 65 years have traditionally not been considered candidates for heart transplantation. However, recent studies have shown similar survival. We evaluated immediate and medium-term results in patients older than 65 years compared with younger patients.

Methods From November 2003 to December 2013, 258 patients underwent transplantation. Children and patients with other organ transplantations were excluded from this study. Recipients were divided into two groups: 45 patients (18\%) aged 65 years and older (Group A) and 203 patients (81\%) younger than 65 years (Group B).

Results Patients differed in age $(67.0 \pm 2.2$ vs. $51.5 \pm 9.7$ years), but gender (male 77.8 vs. $77.3 \% ; p=0.949$ ) was similar. Patients in Group A had more cardiovascular risk factors and ischemic cardiomyopathy (60 vs. $33.5 \% ; p<0.001$ ). Donors to Group A were older ( $38.5 \pm 11.3$ vs. $34.0 \pm 11.0$ years; $p=0.014)$. Hospital mortality was 0 vs. $5.9 \%(p=0.095)$ and 1 - and 5 -year survival were $88.8 \pm 4.7$ versus $86.8 \pm 2.4 \%$ and $81.5 \pm 5.9$ versus $77.2 \pm 3.2 \%$, respectively. Mean follow-up was $3.8 \pm 2.7$ versus $4.5 \pm 3.1$ years. Incidence of cellular/humoral rejection was similar, but incidence of cardiac allograft vasculopathy was higher ( 15.6 vs. $7.4 \% ; p=0.081)$. Incidence of diabetes de novo was similar $(p=0.632)$, but older patients had more serious infections

Keywords

- transplantation

- heart

- heart failure

- surgery

- complications in the 1st year $(p=0.018)$.

Conclusion Heart transplantation in selected older patients can be performed with survival similar to younger patients, hence should not be restricted arbitrarily. Incidence of infections, graft vascular disease, and malignancies can be reduced with a more personalized approach to immunosuppression. Allocation of donors to these patients does not appear to reduce the possibility of transplanting younger patients.
\end{abstract}

\section{Introduction}

Despite major advances in medical and surgical treatment of heart failure, heart transplantation is still the elective treatment for patients refractory to other medical therapies or conventional cardiac procedures. ${ }^{1}$ Due to improved results, the criteria for selection of candidates for transplantation have been gradually extended and the age has been one of the

received

May 27, 2014

accepted after revision

July 4, 2014

criteria more exposed. ${ }^{2}$ However, the upper age limit remains poorly defined, partly due to the high demand for transplantation and the scarcity of organs. Still, advanced age has traditionally been viewed as a contraindication for heart transplantation, despite the improved outcomes recently reported. $^{3}$

Older candidates often have multiple cardiovascular risk factors and deficient physical and psychological conditions

(c) Georg Thieme Verlag KG Stuttgart · New York
DOI http://dx.doi.org/ 10.1055/s-0034-1393959. ISSN 0171-6425. 
and it is known that the immediate results of transplantation are very sensitive not only to the quality of the donor organ but also to the clinical status of the candidate to transplantation. Adequate selection of recipients is essential to the success of a transplantation program.

In this article, we analyzed our own experience and compared the early and late results of cardiac transplantation in two groups of patients, younger and older than 65 years.

\section{Methods}

\section{Definition, Origin, and Collection of Data}

In the period from November 2003 to December 2013, 258 patients were consecutively submitted to heart transplantation at this center. Exclusion criteria for this study included patients previously transplanted with other organs $(n=2)$ and patients younger than 18 years $(n=8)$. In this way, the study population comprised 248 patients, of whom 72 (29\%) were in the intensive care unit, under inotropic support and/ or mechanical assistance, while 176 (71\%) were awaiting transplantation at home.

The data for this patient population were obtained from a national database specifically designed for the prospective registration (online platform) of data of recipient, donor, surgery, immunosuppression protocol, and follow-up of patients undergoing cardiac transplantation.

All surviving patients were followed by regular consultation at the surgical center by a dedicated medical/surgical team, for 1 to 10 years, and none was lost to follow-up. The mean follow-up period in this study was $4.4 \pm 3.1$ years (1,091 patient-years).

\section{Recipients and Donors}

- Table 1 shows the preoperative data of the recipients of the two groups and respective donors, as well as the results of the comparative analysis. When compared with the population of Group B, patients in Group A had a higher rate of cardiovascular risk factors, such as hypertension (53.3 vs. $35.5 \%$; $p=0.026$ ), dyslipidemia (71.1 vs. $43.3 \% ; p=0.001$ ), prior cardiac surgery (44.4 vs. $26.1 \%$; $p=0.015$ ), prior coronary artery bypass grafting (CABG) (24.4 vs. $12.3 \% ; p=0.037$ ), ischemic cardiomyopathy (60 vs. 33.5\%; $p=0.001$ ), and carotid disease (57.8 vs. $34.5 \% ; p=0.004$ ). They also had decreased glomerular filtration rate $(49.2 \pm 15.4$ vs. $63 \pm 23.2 \mathrm{~mL} / \mathrm{min} ; p<0.001$ ), and higher serum creatinine $(1.6 \pm 0.8$ vs. $1.4 \pm 0.5 \mathrm{mg} / \mathrm{dL} ; p=0.099)$. Finally, there were fewer patients in high urgency for transplantation (equivalent to United Network for Organ Sharing (UNOS) status 1A and 1B) in Group A than in Group B (22.2 and 29.5\%, respectively; $p=0.174$ ), and the time on the waiting list was $48.8 \pm 50.0$ vs. $42.3 \pm 44.6$ days, respectively $(p=0.384)$.

There were no major differences in any of the variables between the two groups, with regard to donors. Male donors were most common (66.7 vs. $76.8 \%$ ) and the cause of death was mostly traumatic (51.1 vs. $57.6 \%$ ). However, there was a significant number of older donors for patients in group A ( $38.5 \pm 11.3$ vs. $34.0 \pm 11.0 \%$ years; $p=0.014)$, who also had a tendency for prolonged inotropic (8.9 vs. 3\%; $p=0.067$ ) or ventilator support (20 vs. $10.3 \% ; p=0.072$ ) In total, there were 53 donors older than 45 years (21.4\%), 16 in group $A(35.6 \%)$ and 37 in group $B(18.2 \% ; p=0.014)$. The distribution of donor age versus recipient age is shown in -Fig. 1.

Due to the fact that our region counts with a high donation rate (37.8 donors/million population), $41 \%$ of the donors were local and 59\% distant (mean $=168 \pm 78 \mathrm{~km})$.

\section{Surgical Technique}

All transplantations were performed using the bicaval method, under cardiopulmonary bypass (CPB) and moderate systemic hypothermia $\left(28^{\circ} \mathrm{C}\right)$. To decrease ischemic times, priority is given to the left side heart anastomoses after which the aortic cross-clamp is removed and the anastomoses of the right side are done under perfusion. Typical ischemic time was 40 to 45 minutes for local donation and 90 to 120 minutes for distant harvesting. All patients received an infusion of dobutamine $(5 \mu \mathrm{g} / \mathrm{kg} / \mathrm{min})$ after all the anastomoses were completed, for its chronotropic effect. Need for further inotropic support or posttransplantation mechanical assistance was determined after a period of adequate reperfusion and this decision was based on intraoperative direct visualization of the heart, hemodynamic signs, and transesophageal echocardiogram.

Of notice, as another method to expand the numbers of donors, and based on the large experience of the center with this procedure, concomitant mitral valvuloplasty was performed in 12 donor hearts previously known to have moderate mitral valve disease, 4 in Group A and 8 in Group B. On most occasions, this was done in the form of a suture posterior annuloplasty, but other procedures were performed. $^{4}$

\section{Immunosuppression Therapy and Rejection Monitoring}

Routine induction therapy consisted of mycophenolate mofetil ( $1 \mathrm{~g}$ oral), methylprednisolone sodium succinate (500 mg i.v.) and basiliximab (20 mg i.v.) administered preand during transplantation. After transplantation, patients entered a protocol consisting of a calcineurin inhibitor (mostly cyclosporin, dose-adjusted to blood levels assessed by monoclonal fluorescence polarization immunoassay), mycophenolate mofetil ( $1 \mathrm{~g}$ twice daily), and steroids (125 mg of methylprednisolone intravenously every 8 hours for three doses postoperatively, followed by prednisone, $0.8 \mathrm{mg} / \mathrm{kg} /$ day during the 1 st week and then tapered off in the subsequent 4 weeks to $0.2 \mathrm{mg} / \mathrm{kg} /$ day).

Right ventricular endomyocardial biopsies were performed by a routine protocol or when it was considered to be clinically necessary, and acute cardiac rejection was diagnosed and treated if $\geq 2 \mathrm{R}$ according to the International Society for Heart and Lung Transplantation (ISHLT) classification. ${ }^{4}$

Coronary angiograms were performed at yearly intervals. Cardiac allograft vasculopathy followed the definitions proposed by the ISHLT., 5 
Table 1 Characterization of the recipient and donor populations

\begin{tabular}{|c|c|c|c|}
\hline Recipient group & A & B & $p$ \\
\hline$N$ & 45 & 203 & \\
\hline Age (y, mean \pm SD); range (minimum-maximum) & $67.0 \pm 2.2(65-72)$ & $51.5 \pm 9.7(20-64)$ & $<0.001$ \\
\hline Gender (male) & $35(77.8 \%)$ & $157(77.3 \%)$ & 0.949 \\
\hline Follow-up (y) & $3.8 \pm 2.7$ & $4.5 \pm 3.1$ & 0.146 \\
\hline Wait-list time $(\mathrm{d})$ & $48.8 \pm 50.0$ & $42.3 \pm 44.6$ & 0.384 \\
\hline BMI mean $\left(\mathrm{kg} / \mathrm{m}^{2}\right)$ & $23.8 \pm 3.0$ & $23.8 \pm 3.4$ & 0.996 \\
\hline Diabetes & $15(33.3 \%)$ & $56(27.6 \%)$ & 0.440 \\
\hline Hypertension & $24(53.3 \%)$ & $72(35.5 \%)$ & 0.026 \\
\hline Dyslipidemia & $32(71.1 \%)$ & $88(43.3 \%)$ & 0.001 \\
\hline Prior cardiac surgery & $20(44.4 \%)$ & $53(26.1 \%)$ & 0.015 \\
\hline Ischemic cardiomyopathy & $27(60.0 \%)$ & $68(33.5 \%)$ & 0.001 \\
\hline Dilated cardiomyopathy & $9(20.0 \%)$ & 66 (32.5\%) & 0.098 \\
\hline Peripheral vascular disease & $19(42.2 \%)$ & 64 (31.5\%) & 0.169 \\
\hline Cardiac index $\left(\mathrm{L} / \mathrm{min} / \mathrm{m}^{2}\right)$ & $1.9 \pm 0.4$ & $2.0 \pm 0.5$ & 0.229 \\
\hline Transpulmonary gradient $(\mathrm{mm} \mathrm{Hg})$ & $9.9 \pm 3.5$ & $9.4 \pm 4.8$ & 0.444 \\
\hline Pulmonary vascular resistance (WU) & $3.6 \pm 2.8$ & $3.3 \pm 2.1$ & 0.399 \\
\hline VO2 $\max (\mathrm{mL} / \mathrm{kg} / \mathrm{min})$ & $13.9 \pm 2.5$ & $13.2 \pm 2.8$ & 0.141 \\
\hline Glomerular filtration rate $(\mathrm{mL} / \mathrm{min})$ & $49.2 \pm 15.4$ & $63.0 \pm 23.2$ & $<0.001$ \\
\hline Creatinine level (mg/dL) & $1.6 \pm 0.8$ & $1.4 \pm 0.5$ & 0.099 \\
\hline Urgency/emergency & $10(22.2 \%)$ & $62(30.6 \%)$ & 0.174 \\
\hline \multicolumn{4}{|l|}{ Donor } \\
\hline Age (y) & $38.5 \pm 11.3$ & $34.0 \pm 11.0$ & 0.014 \\
\hline Gender, male & $30(66.7 \%)$ & $156(76.8 \%)$ & 0.154 \\
\hline Inotropic dependence $>1 \mathrm{wk}$ & $4(8.9 \%)$ & $6(3.0 \%)$ & 0.067 \\
\hline Ventilatory assistance $>1 \mathrm{wk}$ & $9(20.0 \%)$ & $21(10.3 \%)$ & 0.072 \\
\hline Donor female/recipient male & $10(22.2 \%)$ & $33(16.3 \%)$ & 0.339 \\
\hline Death by cerebral vascular accident & $15(33.3 \%)$ & $71(34.8 \%)$ & 0.933 \\
\hline Death by brain trauma & $23(51.1 \%)$ & $117(57.6 \%)$ & 0.425 \\
\hline Local procurement & $14(31.0 \%)$ & $88(43.3 \%)$ & 0.180 \\
\hline Distant procurement & $31(69.0 \%)$ & $115(56.7 \%)$ & 0.180 \\
\hline
\end{tabular}

Abbreviations: BMI, body mass index; SD, standard deviation. $\mathrm{P}$ values in bold are those considered significant Note: Univariate comparative analysis of preoperative data of Groups A and B.

\section{Statistical Analysis}

Continuous variables are presented as mean \pm standard deviation and evaluated using the independent Student $t$-test for normally distributed continuous variables and MannWhitney $U$ test for nonnormally distributed continuous variables. Normality was accessed by the Kolmogorov-Smirnov and Shapiro-Wilk tests. Categorical variables are reported as frequency and percentage, and compared using the chi-square test or the Fisher exact test when appropriate. Survival and event-free survival were calculated by the Kaplan-Meier method and comparison between groups obtained by log-rank test. Statistical significance was defined as $p$ value $<0.05$ (two-tailed). Data were analyzed using the IBM Corp. program (released 2011; IBM SPSS Statistics for

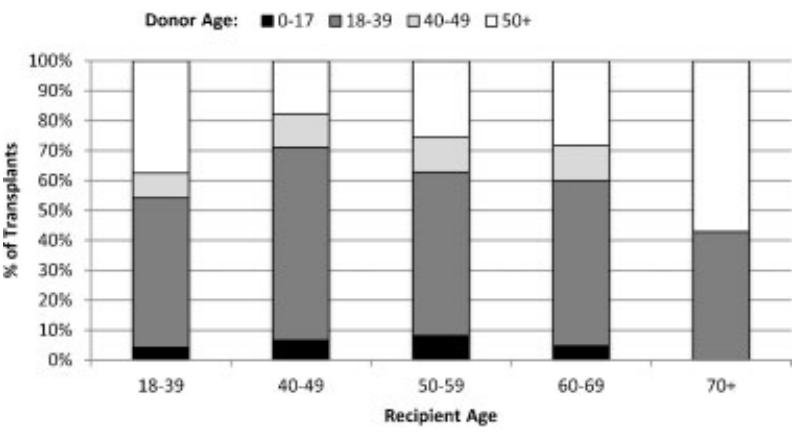

Fig. 1 Adult heart transplantation: donor and recipient age. 
Heart Transplantation in Patients Older than 65 Years Prieto et al.

Table 2 Peri- and postoperative data

\begin{tabular}{|l|l|l|l|}
\hline Recipient group & A & B & P \\
\hline$N$ & 45 & 203 & \\
\hline Total ischemic time (min) & $96.3 \pm 35.2$ & $88.8 \pm 36.4$ & 0.213 \\
\hline CPB time mean (min) & $97.3 \pm 22.8$ & $101.9 \pm 49.2$ & 0.543 \\
\hline Time to extubation (h) & $17.1 \pm 8.9$ & $20.9 \pm 26.4$ & 0.347 \\
\hline Inotropic requirement & $8(17.8 \%)$ & $26(12.8 \%)$ & 0.381 \\
\hline Mechanical assistance & $3(6.7 \%)$ & $10(4.9 \%)$ & 0.636 \\
\hline Hemorrhage & $5(11.1 \%)$ & $9(4.4 \%)$ & 0.079 \\
\hline Mitral valvuloplasty & $4(8.9 \%)$ & $8(3.9 \%)$ & 0.162 \\
\hline Length of hospital stay (d) & $17.4 \pm 14.4$ & $15.3 \pm 15.8$ & \\
\hline
\end{tabular}

Note: Univariate analysis of comparative data of Groups A and B.

Windows, Version 20.0; IBM Corp., Armonk, New York, United States).

\section{Results}

\section{Surgery}

The surgical data, as well as the results of the comparative analysis of the two groups, are shown in -Table 2. No statistically significant differences were observed relatively to times of ischemia ( $96.3 \pm 35.2$ vs. $88.8 \pm 36.4$ minutes; $p=0.213)$, СРВ $(97.3 \pm 22.8$ vs. $101.9 \pm 49.2$ minutes; $p=0.543)$, and mechanical ventilation (17.1 \pm 8.9 vs. $20.9 \pm 26.4$ hours; $p=0.347$ ). There were also no significant differences in the need for inotropic (17.8 vs. $12.8 \%$; $p=0.381)$ or mechanical circulatory (6.7 vs. $4.9 \%$; $p=0.636$ ) support.

There was no hospital mortality in Group A and there were 12 early deaths $(5.9 \%)$ in Group B $(p=0.095)$. The length of hospital stay was similar in both groups $(17.4 \pm 14.4$ vs. $15.3 \pm 15.8$ days; $p=0.454$ ).

After a mean follow-up of $4.4 \pm 3.1$ years (1-10 years; 1,091 patient-years), the overall mortality did not show significant differences between the two groups of patients (28.9vs. 22.7\%; $p=0.375$ ) and the same goes for comparison of in-hospital mortality and death at 6 months, 1 year, and late follow-up between both groups (-Table 3 ). The most frequent causes of death in both groups were infections (11.1 vs. $5.9 \% ; p=0.212$ ) and peripheral vascular disease (4.4 vs. $5.4 \% ; p=0.791$ ).

Overall survival up to 8 years after transplantation did not differ between the older age group and the younger group, as shown in the respective survival curves ( - Fig. $2, p=0.289$ ). Survival rates at 1,5 , and 8 years were $88.8 \pm 4.7,81.5 \pm 5.9$, and $52.3 \pm 12.7 \%$, respectively, and median survival was $6.7 \pm 0.6$ years for older patients; equivalent rates were $86.8 \pm 2.4,77.2 \pm 3.2$, and $72.0 \pm 3.9 \%$, respectively, and median survival was $7.9 \pm 0.3$ years for the younger age group.

\section{Cellular and/or Humoral Rejection, and Graft Vascular Disease}

The data on acute cellular rejection, humoral rejection, and vascular disease of the graft in Groups A and B are shown in - Table 4. One hundred and four patients (42\%) had no

Table 3 Mortality and causes of death

\begin{tabular}{|l|l|l|l|}
\hline Recipient group & A & B & $p$ \\
\hline N & 45 & 203 & \\
\hline Hospital mortality & $0(0.0 \%)$ & $12(5.9 \%)$ & 0.095 \\
\hline Total mortality & $13(28.9 \%)$ & $46(22.7 \%)$ & 0.375 \\
\hline Mortality $<6$ mo & $5(11.1 \%)$ & $21(10.3 \%)$ & 0.879 \\
\hline Mortality $<1 \mathrm{y}$ & $5(11.1 \%)$ & $26(12.8 \%)$ & 0.756 \\
\hline Causes of death & \multicolumn{3}{|l|}{} \\
\hline Cardiac & $1(2.2 \%)$ & $8(3.9 \%)$ & 0.577 \\
\hline Vascular & $2(4.4 \%)$ & $11(5.4 \%)$ & 0.791 \\
\hline Malignant tumor & $2(4.4 \%)$ & $6(3.0 \%)$ & 0.609 \\
\hline Neuropsychiatric & $0(0.0 \%)$ & $4(2.0 \%)$ & 0.342 \\
\hline Infectious & $5(11.1 \%)$ & $12(5.9 \%)$ & 0.212 \\
\hline
\end{tabular}

Note: Univariate analysis of comparative data in Groups A and B. 


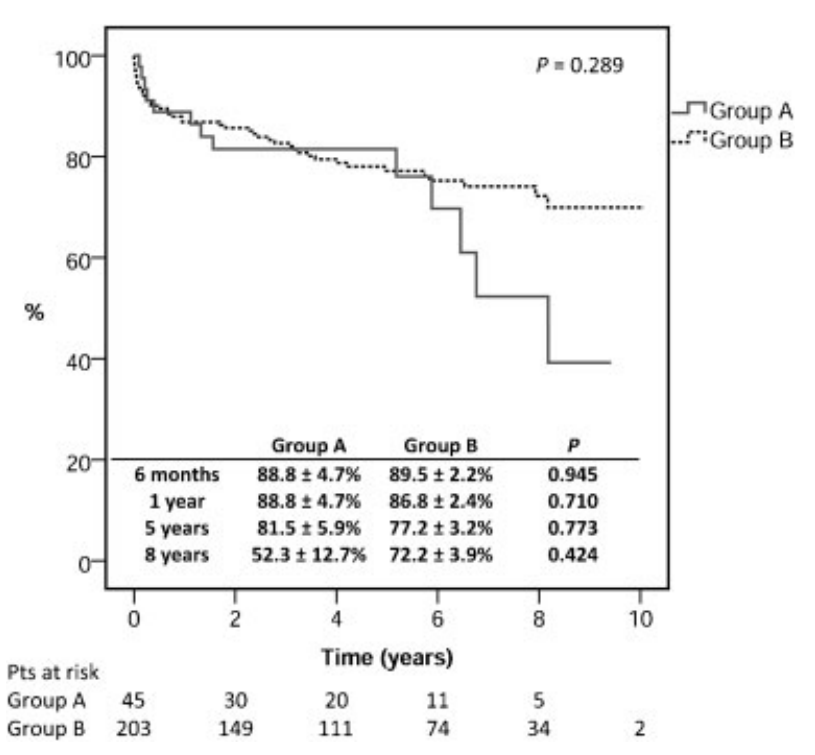

Fig. 2 Overall survival in Groups A and B.

episodes of acute cellular rejection (grade OR of the ISHLT). The remaining patients $(n=144,58 \%)$ had at least one episode of rejection, but it was only mild (1R), requiring no treatment, in 99 of these. The comparative analysis of the two groups showed no statistically significant difference in any of the cellular rejection grades. Forty-five patients (18.1\%), 7 (15.5\%) in Group A and 38 (18.7\%) in Group B, had at least one episode of cellular rejection grade $\geq 2 \mathrm{R}$, the majority (39 cases, $86.7 \%$ ) occurring during the 1 st year. No statistically significant difference $(p=0.652)$ was observed in the survival free from cellular rejection grade $\geq 2 \mathrm{R}$ between Groups $A$ and $B(-$ Fig. 3A).

Humoral rejection was diagnosed in six patients (2.4\%), with no significant difference between the study groups $(p=0.924)$. Graft vascular disease (GVD) was diagnosed in 22 patients (8.8\%), with some difference in the incidence between the study groups ( 15.6 vs. $7.4 \% ; p=0.081$ ). Survival free from GVD was significantly different between the two groups ( $p=0.001$, - Fig. 3B $)$.

\section{New Onset Diabetes and Severe Infections}

The incidence of diabetes de novo in the 1st year after transplantation was $13.3 \%$, with no difference between the two groups (11.1 vs. $13.8 \%$; $p=0.632$ ).

The incidence of serious infections requiring hospitalization and i.v. antibiotics during the 1 st year posttransplantation was significantly higher in Group A (28.9 vs. $14.3 \%$; $p=0.018$ ). In fact, the incidence of pneumonia in the first 6 months was significantly higher in Group A (37.8 vs. $22.7 \%$; $p=0.035)$. Survival free from serious infections was significantly lower in Group A throughout follow-up ( $p=0.028)$, as shown in - Fig. $\mathbf{3 C}$.

\section{Renal Function after Transplantation}

At the time of transplantation, patients in Group A showed a tendency to a lower value of the glomerular filtration rate (GFR), as compared with Group B patients (49.2 \pm 15.4 vs. $63 \pm 23.2 \mathrm{~mL} / \mathrm{min} ; p<0.001)$ and creatinine $(1.6 \pm 0.8$ vs. $1.4 \pm 0.5 \mathrm{mg} / \mathrm{dL} ; p=0.099$ ). At 1 month posttransplantation, a tendency toward recovery of the renal function was observed in both groups, although this was not statistically significant. However, this was followed by progressive deterioration of the GFR, so that from the 1st to the 6th months posttransplantation values dropped significantly in both groups and continued to decline in Group A ( $45.2 \pm 15.5 \mathrm{~mL} / \mathrm{min})$ and, although at a slower pace, in Group B $(58.9 \pm 24.0 \mathrm{~mL} / \mathrm{min})$ up to 12 months. The progression of chronic renal failure to end-stage renal disease required dialysis in four patients. Two of these underwent kidney transplantation.

\section{Malignancies}

Older patients had an increased risk of development of malignancies after transplantation ( 26.7 vs. $13.3 \% ; p=0.026$ ), clearly demonstrated in the 5-year free survival of $67.7 \pm 9.1$ and $87.0 \pm 3.0 \%$, respectively $(p=0.002)(-$ Fig. 3D).

\section{Discussion}

There is still some controversy and even reluctance to offer cardiac transplantation to older patients, especially above

Table 4 Data on rejection and other complications

\begin{tabular}{|l|l|l|l|}
\hline Recipient group & A & B & $p$ \\
\hline$N$ & 45 & 203 & \\
\hline No rejection (0R) & $17(37.8 \%)$ & $87(42.9 \%)$ & 0.532 \\
\hline Acute cellular rejection 2R & $5(11.1 \%)$ & $31(15.3 \%)$ & 0.474 \\
\hline Acute cellular rejection 3R & $2(4.4 \%)$ & $7(3.4 \%)$ & 0.746 \\
\hline Humoral rejection & $1(2.2 \%)$ & $5(2.5 \%)$ & 0.924 \\
\hline Graft vascular disease & $7(15.6 \%)$ & $15(7.4 \%)$ & 0.081 \\
\hline New onset diabetes & $5(11.1 \%)$ & $28(13.8 \%)$ & 0.632 \\
\hline Cancer & $12(26.7 \%)$ & $27(13.3 \%)$ & 0.026 \\
\hline Pneumonia $\leq 6$ mo & $17(37.8 \%)$ & $46(22.7 \%)$ & 0.035 \\
\hline Infections $\leq 12$ mo & $13(28.9 \%)$ & $29(14.3 \%)$ & $\mathbf{0 . 0 1 8}$ \\
\hline
\end{tabular}

Note: Univariate analysis of comparative data in Groups A and B. 

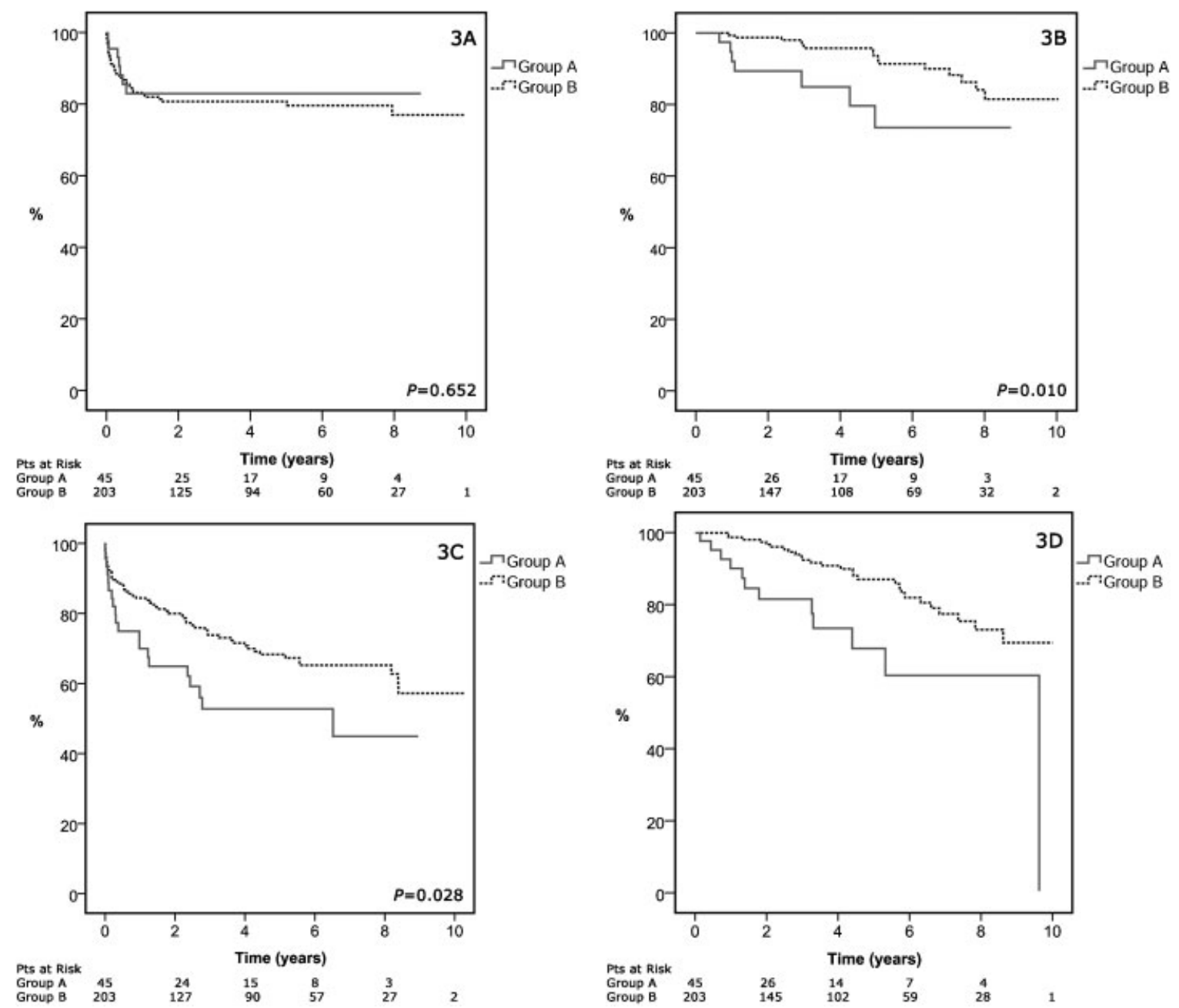

Fig. 3 Survival free from complications related to immunosuppression in Groups A and B. (A) Cellular rejection grade $\geq 2 R$ (ISHLT). (B) Graft vascular disease. (C) Infection. (D) Malignancy. ISHLT, International Society for Heart and Lung Transplantation.

70 years of age, resulting from consideration that they most often have associated comorbidities that influence life expectancy, thus significantly reducing the potential benefit of the procedure. ${ }^{7}$ In addition, there is the presumption of greater difficulties to withstand the rigors of surgery and associated complications, notably those related to immunosuppression. ${ }^{8}$ This limitation is now being questioned, due to the satisfactory results reported in septuagenarians. ${ }^{9}$ In fact, the advances in heart transplantation during the recent decades have considerably changed the clinical practice and outcome in most centers. Yet, the percentage of patients older than 65 years currently being transplanted is $17 \%$ in North America, and in Europe (Eurotransplant) is only 6.7\%. ${ }^{10,11}$

The main argument against cardiac transplantation in old people is their short life expectancy, to which one has to add the scarcity of organs for transplantation. In choosing a donor one is looking for the best result, hence patients with a higher potential of functional recovery, low morbidity, and long survival will naturally have priority. How can we, then, justify transplantation of an old person when the donors are scarce for the young? Which should be the age limit to transplant? These questions are being asked almost daily, as the popula- tion older than 65 years now accounts for approximately $20 \%$ of the total, and greater in some settings. In 2011, UNOS highlighted the significant increase in the percentage of transplanted patients older than 65 years compared with 2001 (17 vs. 10.8\%) and demonstrated a 5-year survival of $74 \%$ for those undergoing heart transplantation in 2005 to $2006 .{ }^{10}$

On the contrary, when one extrapolates the results of the older population (even octogenarians) submitted to conventional cardiac surgery, we find low rates of morbidity and mortality and improved clinical, functional autonomy, and quality of life. ${ }^{12,13}$ In both situations, the decisive factor is the careful selection of the patient. Evidently, in this setting of refractory chronic cardiac failure, often resulting in poor physical and psychological condition, not every older patient can be a candidate for transplantation.

In our experience, there was a natural and undeniably selective inclusion process for older patients in the waiting list for transplantation, which is difficult to characterize and quantify. Transplanted patients older than 65 years were mostly male, with predominantly ischemic heart disease (60\%), a high incidence of carotid and peripheral vascular disease (42 and 57\%), diabetes (33\%), hypertension and 
dyslipidemia, and $44 \%$ of them had previous cardiac surgery (CABG, 25\%). As expected, the renal function was more impaired in these patients than in the younger group. All of these are known important risk factors of morbidity and mortality after transplantation, thus significantly limiting benefit. In the experience of Goldstein et al with heart transplantation in septuagenarians, there was a similar incidence of ischemic heart disease (59\%), yet there were a smaller number of diabetic patients (19\%), fewer patients with peripheral vascular disease (4.5\%), and the serum creatinine levels were slightly lower. ${ }^{14}$

The priority and selection of the donors for these patients is another topic of discussion. In our case, the typical donor assigned to older patients (Group A) was older and 35.6\% of these donors were older than 45 years and had longer mechanical ventilation or inotropic support, thus often considered as suboptimal. Yet, this has not had a negative impact on perioperative and hospital mortality, although a higher incidence of early transient graft dysfunction was apparent (17.8 vs. $12.8 \% ; p=0.381$ ). In fact, there was no early mortality in Group A, but mortality at the end of 1st year was similar in the two groups.

However, the number of infectious episodes who required hospitalization and intravenous antibiotic treatment during the first posttransplant year was higher in Group A (28.9 vs. $14.3 \% ; p=0.018$ ), a circumstance that may have had relevant impact in the overall mortality. The greatest risk of developing serious infections in this group of patients should alert us to the need for taking more forceful prevention measures. Also, relevant was the incidence of malignant pathology in Group $A$, reflected by a significant difference in free survival at 5 years $(67.7 \pm 9.1$ vs. $87.0 \pm 3.0 \% ; p=0.002)$. Finally, a higher incidence of GVD (15.6 vs. 7.4\%) was observed in Group A, with a trend toward statistical significance $(p=0.081)$, a fact that is reinforced when we look at the free-survival curve $(73.4 \pm 9.4$ vs. $93.6 \pm 2.2 \%$, at 5 years; $p=0.010)$. This disease is a multifactorial entity, which is more aggressive in individuals with risk factors or predicted cardiovascular disease, more present in older patients.

By contrast, the incidence of acute cell rejection that required treatment $(\geq 2 \mathrm{R})$ was similar in both groups throughout the follow-up. This appears to be a common occurrence in many studies in this age group. ${ }^{15,16}$ The decline in immune competence that occurs with aging is associated with a progressive reduction in the generation of new $T$ and $B$ lymphocytes, with the consequent loss of diversity and functional competence. ${ }^{17}$ It establishes a dramatic reduction in responsiveness as well as disruption of the function. Both facts contribute to lower rejection rates but to the increased incidence in morbidity and mortality from infectious diseases and cancer. ${ }^{18,19}$

The understanding of this immunosenescence thus requires a different attitude in the handling of the immunosuppression in this age group. Therefore, it has been suggested by others that the immunosuppression load be reduced so as to minimize its side effects without increasing the risk of rejection, especially in the 1 st year posttransplant, when it could be expected to diminish the number of infectious episodes and its impact on mortality. Similarly, it could also reduce the incidence of malignancies and GVD. ${ }^{20}$ We were aware of this phenomenon early in this experience and the results reported herein may already incorporate the benefits thereof.

Also analyzed in this study was the evolution of the renal function, measured by the serum creatinine level and creatinine clearance, during the 1 st year, as it would be at this time that one would expect greater divergence. In both groups, there was a stabilization or improvement of the renal function immediately after transplantation, but this was followed by a gradual deterioration of the GFR over the 1st year, greater in Group A (42.2 \pm 15.5 vs. $58.9 \pm 24.0 \mathrm{~mL} / \mathrm{min} ; p=0.002)$. An eventual reduction of the immunosuppression doses may also have an impact here. ${ }^{21,22}$

Despite these complications, the survival curve in the medium term is similar in older and younger transplant patients, although we appear to witness a decrease in the long-term survival, which has to be naturally expected in this population. Increased and differentiated care, not only in the selection of candidates for transplantation but also in postoperative care and follow-up (medium and long term), conditions we can only find in units with high volume and experience, will almost certainly improve outcomes. ${ }^{23,24}$

A last comment, paradoxically, the simple existence of these older candidates in the waiting list, parallel to better donor procurement, appears to facilitate the use of better donors in younger candidates, perhaps raising questions of ethical order, although the use of marginal donors has been demonstrated to have an acceptable outcome also in younger individuals. $^{25}$

\section{Conclusion}

The number of patients awaiting heart transplantation has been increasing, unlike the supply of donors. This panorama requires strengthening of the borders of donation and the need to consider responsibly and pragmatically the allocation of available organs. This situation becomes more complex when there is an increase in the number of older patients who are potential candidates for transplantation. In our experience, the results obtained in older patients were similar to those in younger recipients, at least in the medium-term survival, but with significantly higher rates of important morbidity. The results could perhaps be improved by reducing the intensity of immunosuppression in this population.

The allocation of donors to this older group does not seem to reduce the overall success of transplantation, but it is difficult to assess the impact on the younger population awaiting transplantation. The key will be a more rigorous, responsible, and pragmatic selection of both patients and donors.

\section{References}

1 McMurray JJ, Adamopoulos S, Anker SD, et al; ESC Committee for Practice Guidelines. ESC Guidelines for the diagnosis and treatment of acute and chronic heart failure 2012: The Task Force for the Diagnosis and Treatment of Acute and Chronic Heart Failure 
2012 of the European Society of Cardiology. Developed in collaboration with the Heart Failure Association (HFA) of the ESC. Eur Heart J 2012;33(14):1787-1847

2 Mehra MR, Kobashigawa J, Starling R, et al. Listing criteria for heart transplantation: International Society for Heart and Lung Transplantation guidelines for the care of cardiac transplant candidates -2006. J Heart Lung Transplant 2006;25(9):1024-1042

3 Lund LH, Edwards LB, Kucheryavaya AY, et al; International Society for Heart and Lung Transplantation. The Registry of the International Society for Heart and Lung Transplantation: Thirtieth Official Adult Heart Transplant Report-2013; focus theme: age. J Heart Lung Transplant 2013;32(10):951-964

4 Prieto D, Antunes P, Antunes MJ. Donor mitral valve repair in cardiac transplantation. Transplant Proc 2009;41(3):932-934

5 Stewart S, Winters GL, Fishbein MC, et al. Revision of the 1990 working formulation for the standardization of nomenclature in the diagnosis of heart rejection. J Heart Lung Transplant 2005; 24(11):1710-1720

6 Mehra MR, Crespo-Leiro MG, Dipchand A, et al. International Society for Heart and Lung Transplantation working formulation of a standardized nomenclature for cardiac allograft vasculopathy2010. J Heart Lung Transplant 2010;29(7):717-727

7 Weiss ES, Allen JG, Arnaoutakis GJ, et al. Creation of a quantitative recipient risk index for mortality prediction after cardiac transplantation (IMPACT). Ann Thorac Surg 2011;92(3):914-921, discussion 921-922

8 Hong KN, Iribarne A, Worku B, et al. Who is the high-risk recipient? Predicting mortality after heart transplant using pretransplant donor and recipient risk factors. Ann Thorac Surg 2011;92(2): 520-527, discussion 527

9 Daneshvar D, Czer LS, Phan A, et al. Heart transplantation in patients aged 70 years and older: a two-decade experience. Transplant Proc 2011;43(10):3851-3856

10 Colvin-Adams M, Smithy JM, Heubner BM, et al. OPTN/SRTR 2012 Annual Data Report: heart. Am J Transplant 2014;14(1, Suppl 1): 113-138

11 Eurotransplant Annual Report 2012 (April 2013). Available online at www.eurotransplant.org. Accessed on April 16, 2014

12 Ditchfield JA, Granger E, Spratt P, et al. Aortic valve replacement in octogenarians. Heart Lung Circ 2014: (e-pub ahead of print)
13 Sumi M, Ariyoshi T, Miura T, et al. Are octogenarians in good condition after cardiac valvular surgery? Ann Thorac Cardiovasc Surg 2014 (e-pub ahead of print)

14 Goldstein DJ, Bello R, Shin JJ, et al. Outcomes of cardiac transplantation in septuagenarians. J Heart Lung Transplant 2012;31(7): 679-685

15 Morgan JA, John R, Weinberg AD, et al. Long-term results of cardiac transplantation in patients 65 years of age and older: a comparative analysis. Ann Thorac Surg 2003;76(6):1982-1987

16 Blanche C, Blanche DA, Kearney B, et al. Heart transplantation in patients seventy years of age and older: a comparative analysis of outcome. J Thorac Cardiovasc Surg 2001;121(3):532-541

17 Hakim FT, Gress RE. Immunosenescence: deficits in adaptive immunity in the elderly. Tissue Antigens 2007;70(3):179-189

18 Fulop T, Kotb R, Fortin CF, Pawelec G, de Angelis F, Larbi A. Potential role of immunosenescence in cancer development. Ann N Y Acad Sci 2010;1197:158-165

19 Malaguarnera L, Cristaldi E, Malaguarnera M. The role of immunity in elderly cancer. Crit Rev Oncol Hematol 2010;74(1):40-60

20 Hakim FT, Gress RE. Immunosenescence: immune deficits in the elderly and therapeutic strategies to enhance immune competence. Expert Rev Clin Immunol 2005;1(3):443-458

21 Lindelöw B, Bergh CH, Herlitz H, Waagstein F. Predictors and evolution of renal function during 9 years following heart transplantation. J Am Soc Nephrol 2000;11(5):951-957

22 Ojo AO, Held PJ, Port FK, et al. Chronic renal failure after transplantation of a nonrenal organ. N Engl J Med 2003;349(10): 931-940

23 Arnaoutakis GJ, George TJ, Allen JG, et al. Institutional volume and the effect of recipient risk on short-term mortality after orthotopic heart transplant. J Thorac Cardiovasc Surg 2012;143(1): 157-167, e1

24 Weiss ES, Meguid RA, Patel ND, et al. Increased mortality at lowvolume orthotopic heart transplantation centers: should current standards change? Ann Thorac Surg 2008;86(4):1250-1259, discussion 1259-1260

25 Lietz K, John R, Mancini DM, Edwards NM. Outcomes in cardiac transplant recipients using allografts from older donors versus mortality on the transplant waiting list; implications for donor selection criteria. J Am Coll Cardiol 2004;43(9):1553-1561

Invited Commentary

\section{Age Over 65: To Transplant or Not to Transplant?}

\author{
Alexander M. Bernhardt ${ }^{1}$ Hermann Reichenspurner ${ }^{1}$ \\ ${ }^{1}$ Department of Cardiovascular Surgery, University Heart Center, \\ Hamburg, Germany
}

Orthotopic heart transplantation (OHT) is still the only curative treatment for patients with terminal heart failure. However, widespread use of heart transplantation has been increasingly limited by the growing discrepancy between the number of patients on the waiting list and the number of available organs. On the contrary, as population of people older than 65 years is increasing these days, the prevalence of heart failure is increasing, leading to more patients with terminal heart failure. The recent article ${ }^{1}$ shows similar out-
Address for correspondence Hermann Reichenspurner, MD, PhD, Department of Cardiovascular Surgery, University Heart Center Hamburg, Martinistraße 52, 20246 Hamburg, Germany (e-mail: hcr@uke.de; www.uhz.de).

comes in heart transplant recipients older than 65 years compared with younger patients. Previous publications on survival outcomes of OHT in older patients showed conflicting results. ${ }^{2-10}$

Some large-cohort registry analyses-for example, the International Society for Heart \& Lung Transplantation (ISHLT) registry-have identified older age as a risk factor for both early and late mortality after $\mathrm{OHT}^{2,3,6-8}$ In older recipients, death from graft failure together with cardiac 
allograft vasculopathy and acute rejection becomes less common, whereas death from nonlymphoma malignancy, renal failure, organ failure, and infection increases. ${ }^{6}$ Other single-institutional experiences have demonstrated that with careful patient selection, OHT can be performed in elderly patients with mortality and morbidity equivalent to younger recipients as reported in other publications. ${ }^{1,5,9}$ Furthermore, multicenter data have demonstrated acceptable long-term outcomes in selected older recipients. ${ }^{10}$ However, despite the overall similar results in selected older transplant recipients compared with younger patients, the conflict of transplanting in older patients still remains. ${ }^{11}$ The waiting time and urgency for a patient on the waiting list has risen over the last years. The increasing organ shortage, which entails longer waiting time and the fact that sicker patients are transplanted, is considered to be an important factor for the declining results over the last years. The criteria that account for the highurgency status are almost the same as the risk factors for 1-year mortality. ${ }^{6}$ As a consequence, the expected outcome after transplantation has gained increasing attention both in the transplant community and in the general public. ${ }^{12}$

In fact, next to the urgency of the transplantation the chances of success are explicitly named as the second important allocation principle in the German transplant law. Recently, allocation based on urgency and outcome has already been realized for lung transplantation by the introduction of the lung allocation scores (LAS) in 2011. The initial experiences with the LAS are promising; therefore, a cardiac allocation score has currently been developed. ${ }^{13}$ The consequence will be that a younger patient with a higher probability of long-term survival will have a higher chance of getting a transplant than a patient of advanced age, for example, older than 65 years. Older recipients will not be excluded from heart transplantation in general, but the rare organs will primarily be allocated to younger patients. For older patients, an "old-for-old" program could be introduced. Then, hearts from younger donors would be reserved for younger recipients with a higher probability of favorable long-term outcome. Alternatively, older patients could receive a left ventricular assist device, either as destination therapy or as bridge-to-transplantation. A recent UNOS analysis demonstrated that $\mathrm{OHT}$ recipients aged 70 years and older who were bridged with ventricular assist device had outcomes equivalent to patients younger than 70 years. ${ }^{3}$

\section{References}

1 Prieto D, Correia P, Batista M, Antunes M. Heart transplantation in patients over 65 years of age. Worthwhile or wastage of organs? Thorac Cardiovasc Surg 2014

2 Weiss ES, Allen JG, Arnaoutakis GJ, et al. Creation of a quantitative recipient risk index for mortality prediction after cardiac transplantation (IMPACT). Ann Thorac Surg 2011;92(3):914-921, discussion 921-922

3 Kilic A, Weiss ES, George TJ, et al. What predicts long-term survival after heart transplantation? An analysis of 9,400 ten-year survivors. Ann Thorac Surg 2012;93(3):699-704

4 George TJ, Kilic A, Beaty CA, Conte JV, Mandal K, Shah AS. Septuagenarians bridged to heart transplantation with a ventricular assist device have outcomes similar to younger patients. Ann Thorac Surg 2013;95(4):1251-1260, discussion 1260-1261

5 Daneshvar D, Czer LSC, Phan A, et al. Heart transplantation in patients aged 70 years and older: a two-decade experience. Transplant Proc 2011;43(10):3851-3856

6 Lund LH, Edwards LB, Kucheryavaya AY, et al; International Society for Heart and Lung Transplantation. The Registry of the International Society for Heart and Lung Transplantation: Thirtieth Official Adult Heart Transplant Report-2013; focus theme: age. J Heart Lung Transplant 2013;32(10):951-964

7 Tjang YS, van der Heijden GJMG, Tenderich G, Körfer R, Grobbee DE. Impact of recipient's age on heart transplantation outcome. Ann Thorac Surg 2008;85(6):2051-2055

8 Favaloro R, Diez M, Bertolotti A, et al. Orthotopic heart transplantation in elderly patients: a 10-year experience at a single center. Transplant Proc 2004;36(6):1692-1694

9 Blanche C, Blanche DA, Kearney B, et al. Heart transplantation in patients seventy years of age and older: a comparative analysis of outcome. J Thorac Cardiovasc Surg 2001;121(3):532-541

10 Kilic A, Weiss ES, Yuh DD, Shah AS, Conte JV. Factors associated with 5-year survival in older heart transplant recipients. J Thorac Cardiovasc Surg 2012;143(2):468-474

11 Stevenson LW. The urgent priority for transplantation is to trim the waiting list. J Heart Lung Transplant 2013;32(9):861-867

12 Bernhardt AM, Rahmel A, Reichenspurner H. The unsolved problem of organ allocation in times of organ shortage: the German solution? J Heart Lung Transplant 2013;32(11):1049-1051s

13 Smits JM, de Vries E, De Pauw M, et al. Is it time for a cardiac allocation score? First results from the Eurotransplant pilot study on a survival benefit-based heart allocation. J Heart Lung Transplant 2013;32(9):873-880 